\title{
Liars, Cheaters, and Short-Haired Girls: Gender Identity Denial of Young Athletes
}

\author{
Julie Minikel-Lacocque \\ University of Wisconsin-Whitewater
}

\begin{abstract}
Gender-based discrimination in sport is omnipresent and manifests in various forms, including unequal pay, disparate access to facilities, and imbalanced media exposure. This discrimination also extends to those female athletes who do not meet stereotypical notions of how females should look and how they should move on the sporting field. Four gender nonconforming youth athletes who have faced gender and gender-identity discrimination in sport were recruited for this study, as well as their families and two of their coaches. A qualitative case study was conducted and data from in-depth interviews with each participant, one focus group with the young athletes, and observational field notes are analyzed. Through the lens of Critical Feminist Theory, this study examines the gender and gender-identity discrimination these young athletes have endured, the perpetrators of which are adults charged with organizing and regulating youth sport. The study finds that these athletes are repeatedly accused of lying about their identities, that they are often subjected to gender identity denial, and that their bodies are routinely policed and objectified. Implications for institutions of higher education, sport management, coaches, referees, and fans are discussed and include targeted education on nuanced understandings of gender, sex, misgendering, and gender identity denial. This study also calls for sport to believe youth athletes regarding their identities as well as for a re-examination of the gendered structure of youth sport.
\end{abstract}

Keywords: coaching, coaching education, gender nonconfirming, sport, youth sports

What makes a lady? Does it mean if you are wearing skirts or dresses you're a lady? No. What kind of a lady is that? Yeah, I'm a lady. There's nothing I can say. Yes, I'm a lady. I have those cards of being a lady. — Caster Semenya, South African track star

Women and girls in sport remain in an inferior position to that of men and boys and continue to face systematic discrimination. This is the case with regard to pay, access to quality facilities, media exposure, and harmful stereotypes. It is also true with regard to the phenomenon of gender-policing and sex control (Krane, 2019) whereby suspicious females (read: skilled, strong, and successful) have long been subjected to forced gender verification processes by which many have been banned from their sport. The most wellknown contemporary case of gender policing in sport is that of Caster Semenya, the South African track star, quoted above. Semenya has been targeted for presenting stereotypically male attributes, such as a low voice, muscular build, and record-fast racing times. Despite her and her family's insistence that she is female, sport governing bodies have consistently doubted her identity. And, although she was not always the fastest woman in international competition, she was barred from competing and ordered to undergo gender verification testing. The results of the tests would determine if she would ever be eligible to compete again. ${ }^{1}$

Such drastic measures to police "suspicious females" are not limited to the world stage of adult professional athletes, however. In 2017, The New York Times reported on the case of Mili Hernandez, a talented eight-year-old female soccer player from

Minikel-Lacocque (minikelj@uww.edu) is an Associate Professor in the Department of Curriculum and Instruction at the University of Wisconsin-Whitewater, Whitewater, WI, USA.
Nebraska with short hair (Mele, 2017). Her team was disqualified after tournament officials decided she was a boy playing on an allgirls team. Despite her and her parents' insistence that she was being truthful about her identity and was rostered correctly as female, she and her team were barred from the tournament.

This article addresses an under-studied population and adds to our understanding of young female athletes' experiences with gender discrimination in sport through examining instances of homegrown varieties of sex control and gender identity discrimination. The targets of this discrimination are four short-haired girls, 10-12 years old, who are skilled athletes on the same competitive all-girls soccer team. The perpetrators are the very adults charged with supporting the development of these athletes as well as encouraging their continued love of sport: coaches, parents, referees, and adult sideline fans.

\section{Gender and Sports in Context}

It is first necessary to define terms that are often essentialized, conflated and, thus, misunderstood, as well as to clarify how they are used in this article. Each definition below, unless noted, is found in the glossary of Krane's (2019) work. Gender is defined as "a culturally constructed concept referring to behaviors, social roles, and attitudes that distinguish among people by ascribing them feminine and masculine characteristics" (p. 242). Gender expression can be defined as "how individuals convey their gender through outward behaviors, comportment, name, pronouns, clothing, attitude, hair style, etc.” (p. 242). Sex assigned at birth, which may or may not coincide with one's gender, is "a term used to distinguish between one's interpreted or designated sex (typically based on the appearance of their genitals at birth" (p. 247). Lastly, the term gender nonconforming "describes people whose gender 
expression is not consistent with cultural expectations for their sex, such as feminine males or masculine females. Also describes those who identify outside the gender binary" (p. 242). Finally, gender identity can encompass more than the male/female binary, is a continuum, and is not necessarily fixed. As Miller (2019) attests, "Gender identity is neither singular nor easily located within rigid or fixed gender binaries" (p. 50).

\section{Gender Discrimination and Stereotyping in Sport}

Messages perpetuating the inferior role of females in sport as well as stereotypical notions of acceptable ways to perform femininity persist in popular culture. These messages are omnipresent and insidious in their ability to inform how gender is perceived and therefore constructed. Indeed, a critical look at media writ large, commercial spaces, advertising, and product promotion in its various forms reveals oppressive notions about the "right" way for females to look and act. For example, physicality, strength, and intellect are commonly linked to masculinity. Females are expected to appear in very specific, "acceptable" ways; and, these expectations apply to bodies, clothing, make-up, and hair length.

Media coverage of sport is no exception. Attention given to women's sports is a fraction of that given to male sports, and, when the media does cover female sports, the coverage is often problematic. Longitudinal studies on media coverage and gender have consistently found that sports networks dedicate very little time to women's sports; indeed, the percentage of airtime has remained in the single digits (Cooky, Messner, \& Musto, 2015). What's more, the scant media coverage of women's sports often reinforces gender stereotypes and female subjugation by sexualizing female athletes, emphasizing their physical appearance, and deemphasizing their athleticism and strength (Messner, 2007; Weber \& BarkerRuchti, 2012). As Cooky et al. explain, "It would appear that the sports media covers women's sports . . . in ways that conform to conventional gender norms that position women as either objects of men's (hetero)sexual desire or mothers, wives, or girlfriends" (2015, p. 280). Although interrogating the origins and full scale of gender discrimination and how it relates to sport is outside the scope of this article, the gendered messages that abound within popular culture - and are thus perpetuated-are cause for concern and must be interrogated in order to understand the context in which the experiences of this study's participants are situated.

\section{Gender, Sex, and Policing in Sport}

The stereotyping, discrimination, and lack of equality discussed above have bolstered the ideas that females should look and act in certain ways and that females are inferior to males in the sports arena. Thus, these ideas also support the notions that females can (and should) be easily identified as such through their appearance and that the "weaker sex" (read: females) must be protected from the "stronger sex" (read: male) when it comes to sport. Finally, these ideas also perpetuate the veracity of gender and sex binaries. The above, when taken together, has created fertile ground for the practice of "verifying" one's sex and gender to continue to exist.

It is significant that various versions of this "verification" process have existed at the highest levels of sport since the early 1900s. The purpose of these tests, claimed the International Association of Athletics Federation (IAAF)—now named World Athletics — and the International Olympic Committee (IOC), was to protect female athletes from competing against male athletes who might be "masquerading" as females in all-female events
(Cooky \& Dworkin, 2013; Peiper, 2016). Importantly, the labels used by the IOC to refer to this testing have changed over the years. Examples include, "sex verification," "sex check," "sex control," "femininity testing," and "gender testing" (Pieper, 2016, p. 3). It is important to note the conflation of the notions of sex and gender represented in these labels as well as in the accompanying policies, which point to common misunderstanding and simplification of sex and gender. Thus, a clarification of the terms gender policing and sex control used in this article is necessary. Krane (2019) defines gender policing as "social and cultural pressures that enforce normative gender expression. It typically is imposed on individuals perceived as performing gender inconsistent with cultural expectations for people of their assigned sex" (p. 242). Sex control (Bavington, 2019), on the other hand, is the process used to determine in which category an elite female athlete "fits" and is allowed to compete. This term "shift[s] the gaze from women made vulnerable by these polices to the powerful in control of their development" (p. 184-5). As seen below, the young participants in this study have been targets of gender policing and of an amateur version of sex control.

\section{Gender Nonconforming Youth in Sport}

The nuanced, complex nature of sex and gender illustrated above has yet to become part of mainstream understandings. And, in a society that generally recognizes two sexes and two genders, and expects people to perform each of these "correctly," it can be difficult for gender nonconforming youth, or, for those who are, in the words of Miller (2019), "gender identity complex." Specifically, as reported in the Human Rights Campaign's (2018) Gender Expansive Youth Report, of the more than 5,600 youth surveyed with "gender expansive identities," 97\% have trouble sleeping at night, $88 \%$ felt down in the last week compared to $72 \%$ of cisgender LGBQ youth, and $84 \%$ felt hopeless or worthless in the last week compared to $66 \%$ of cisgender LGBQ youth.

While sport is commonly considered a welcoming space for "tomboys" and gender nonconforming females, the discussion above indicates that sport is not always a safe haven for these athletes and begs an interrogation of the gendered structure of sport. With the exception of co-ed youth teams, sport is strictly organized under the exclusive gender binary. In fact, as young athletes become increasingly dedicated to their sport, and as the level of play intensifies, co-ed teams are no longer an option-there are only boys and girls teams to choose from. Many scholars of sport argue for the abolishment the gender binary system in sport, and offer a variety of inclusive organizing systems (see, for example, Anderson, 2002; Kane, 1995; Seidman, 1997; Travers, 2006; Travers, 2008; Travers, 2014; Travers, 2019). Moving away from the gender binary in sport, they argue, would make space for the acceptance of those who are "gender identity complex" youth. Specifically, Travers (2014) recommends that within a sexsegregated sport structure, youth should be allowed to play on either team, and that policy and practice should dictate that no "gender questions" ever be asked of the athletes.

\section{A Critical Perspective on Gender Identity Discrimination and Sport}

I approach this work from a critical perspective, paying close attention to power dynamics as well as maintaining a focus on social justice. As Smith (2005) explains, critical theorists hope that research might "lead to emancipation and social justice for 
oppressed groups if research understood and addressed unequal relations of power" (p. 88). Specifically, the lens of critical feminist theory (MacKinnon, 1983; Oleson, 2011; Oleson, 2018) is helpful here. Critical feminist theory falls under the umbrella of "feminist cultural studies," which, in general, is an area committed to "understanding sex, gender, and sexuality as well as responding to the inequalities based on these identities" (Waldron, 2019, p. 20). Four central tenets of feminist cultural studies are as follows: “a) emphasis on everyday social practices, b) [emphasis on] unequal gendered power dynamics, c) [emphasis on] hegemonic processes, and d) [emphasis on] how normative sex, gender, and sexuality are privileged" (Waldron, 2019, p. 20).

This framework calls us to ask questions such as, Whose knowledge counts? Who has the right to determine the gender identities of gender nonconforming athletes? What are the experiences of young athletes and their advocates when their right to define their own gender identities is denied? Interrogations of historical and contemporary power structures in sport and coaching as they relate to gender and gender identity discrimination are necessary if we are to work toward equity, which includes a deeper understanding of gender itself. It is my hope that this study, which privileges the experiences and perspectives of the athletes themselves and their supporters, contributes to a necessary reexamination of common understandings of gender identity, current structures of youth sport, coaching preparation programs, coaching practices, and sport club coaching directors' responsibilities as they relate to the rights of young athletes.

Informed by this framework, the study's guiding questions are:

1. What are the lived experiences of these young gender nonconforming athletes with regard to their gender identities in the context of soccer?

2. How do the four focal players think, feel, and talk about the various instances of discrimination they have endured in relation to soccer?

3. How do the players' families and coaches experience these instances of discrimination?

Implications for sports-related preparation programs at institutions of higher education as well as implications for coaches, referees, club coaching directors and managers, and spectators are discussed.

\section{Method}

The study took place in a mid-sized city in the U.S. as well as many of the locations to which the team traveled for games and tournaments over the span of approximately two years. This study is based on approved human subjects research, and approval was obtained through the Institutional Review Board (IRB). All names and places have been changed to protect the participants' identities.

Qualitative case study forms the methodological foundation of this study, as this foundation recognizes the valuable perspectives of those who have been othered and oppressed by gender and gender identity discrimination and is in line with the theoretical framework discussed above. In other words, critical feminist theory, situated within postmodern epistemologies, calls us to learn from those who are oppressed, and to believe and value their experiences and perspectives - and rejects one objective truth. By asking, through in-depth interviews, each young athlete and members of their support system about their experiences of oppression, I aim to center their voices. And, by centering the voices of these young athletes who are oppressed by adults in their sport, my goal is to privilege their voices without "replicating oppression and privilege in the process" (Oleson, 2018, p. 160). By valuing their experiences, I hope their own multiple and subjective truths are voiced and thus become a part of working toward social justice for these and other nonconforming athletes and children.

To examine the experiences of the four focal players, their families, and their coaches, I conducted a qualitative case study, a methodology in which "the case is at center stage, not variables" (Schwandt, 2001, p. 23). Specifically, I conducted a "collective case study," (Stake, 2005), in which the experience of each focal player is considered a "case." As Stake (2005) describes, cases are chosen because "it is believed that understanding them will lead to better understanding, and perhaps better theorizing, about a still larger collection of cases" (445-6).

\section{Focal Participants}

The four focal children, ages 10-12 at the time of data collection, each chose their pseudonyms for the study: Alex, Bobetta, Emily, and Sam. These children are talented athletes who play on the same competitive all-girls soccer team, within a club called "The Eagles." Each child's sex assigned at birth is female. None of the children has transitioned to male, and, throughout the study, each child publicly identified as female. That said, it is important to recall the above discussion regarding gender and its complexity; thus, we should be careful not to assume that one's identity fits neatly within the binary, or that it will continue to do so throughout the span of one's lifetime.

Each child fits within Krane's (2019) definition of gender nonconforming discussed above in that each child's gender expression does not match societal expectations for their sex. Each has a short haircut, and each has been asked various times by peers and adults, "Why do you have a boy haircut?" Each dresses in genderneutral, or in stereotypically 'male' clothing - usually consisting of t-shirts, athletic pants, and athletic shoes-and each has been asked, "Why do you dress like a boy?" I purposely did not explicitly ask the children how they identify with regard to gender. This is because I learned from the children's parents that at least some of the focal players were experiencing significant stress related to defining their gender identity and to frequently being asked to explain and defend their gender identity. These children decidedly did not want to be asked about it. During interview conversations, however, all of the focal players referred to themselves with female pronouns and referred to themselves as a 'girl,' unsolicited by questions from me. Each child has a White race identity, as indicated by their parents in interviews. All other participants have a white race identity and are cisgender.

\section{Researcher Subjectivity}

As female and former athlete, I have experienced gender-based discrimination writ large, and specifically related to my participation in sport. As a mother of athletes, I have witnessed genderbased discrimination with regard to sport. I am also, however, a cisgender female who has not been misgendered nor have I been the target of gender identity denial. All of this is important to recognize. As I have argued elsewhere, as researchers we become part of a relationship formed through the research, and as such, we are part of the research (Minikel-Lacocque, 2019).

I continually reflected on kept analytical memos on the relationships between the participants and myself, and, on how, given my identities mentioned above, I might be biased toward 
feeling outrage at what the children faced as well as a protectiveness of the young participants. I tried to keep this in check by frequently checking with participants and consulting with colleagues (see the section, Data Analysis). Unavoidably, however, we bring our own subjectivity to the research process, and "objective knowledge" is unattainable, nor is it the goal. Ultimately, it is my interpretation of the participants' experiences that gets told.

\section{Participant Recruitment and Selection}

Through my connection to sport, I became aware of some of the gender identity discrimination the focal players endured. I also become aware, through the larger soccer community, that the coaches of these players were said to be very supportive of the players. Thus, due to my interest in learning about the experiences and perspectives of these young players of this particular type of discrimination, as well as of members of their support system (in this case, parents, siblings, and coaches), the recruitment was targeted and specific. I approached the parents of the four focal players through a combination of face-to-face interactions and email to gauge their interest in participating in a study. Each parent enthusiastically agreed to participate, and then checked with their children to see if they would also like to participate, and each child immediately agreed. Then, through face-to-face interactions, I approached two head coaches within the players' club, who also immediately agreed to participate. I also approached two siblings of the players, who also agreed to participate. Consent was obtained from parents and coaches and assent was obtained from children through their parents before data collection began. Consent and assent were obtained through face-to-face interactions to exchange paperwork and signatures were obtained on documents in paper form. All participants remained in the study for its entirety. Data collection was halted when saturation was reached. Rapport was easily developed due to mutual acquaintances in the sport community; in other words, the participants and I had varying levels of familiarity before the study began.

\section{Data Collection}

In-depth, semi-structured interviews and observation are the central modes of inquiry for this study. I conceive of the in-depth interview (Fontana \& Frey, 1998) as a complex "craft" (Gubrium, Holstein, Marvasti, \& McKinney, 2012) as opposed to a skill one can learn from a training manual. In order to successfully and sensitively engage in in-depth interviewing, interviewers must reflect on their role in the conversation, their assumptions, and their subjectivity (Johnson \& Rowlands, 2012; Roulston, 2010; Roulston, 2012) among other things, all with an awareness of the interviewee's well-being (Minikel-Lacocque, 2019).

Specifically, I conducted one to two interviews with each of the four focal children; one to two interviews with the parents of the focal children; one interview each with two siblings of the focal children; one interview each with two coaches of the focal children; and one focus group which included each of the four focal children. Each of these interviews were in-depth, semi-structured interviews and lasted between 45 minutes and 2 hours and took place in public spaces such as cafes or libraries. In total, 16 interviews were conducted. In addition, I conducted over 200 hours of observation of the focal children and kept detailed field notes. These observations took place on the soccer field, and I was either on the sideline or in the stands. At times during these observations, I interacted with the parents of the focal players. Those interactions were also recorded in field notes.

\section{Data Analysis}

Interviews were transcribed verbatim and analyzed along with the field notes I recorded after each interview and each observation. I coded these documents for salient themes. Coding is iterative and is "not a linear process" (Charmaz, Thornberg, \& Keane, 2018, p. 424), and it begins when data collection begins. In other words, I created codes and categories of data "by scrutinizing and interacting" (Charmaz et al., 2018, p. 424) with the data, and continued to do so, thereby refining the codes, throughout the study. In addition, throughout data collection and analysis I wrote analytical memos (Glense \& Peshkin, 1992) through which I was able to recognize and refine emerging themes. Through memo writing, "researchers gain analytic distance from data and create an intellectual workspace for documenting their analysis" (Charmaz et al., 2018, p. 429).

As a critical feminist qualitative researcher exploring sensitive topics with minors and their adult supporters who have experienced gender-based discrimination, it is my responsibility to check my representation of the participants with the participants themselves in order to be sure I have responsibly represented my participants and their experiences. Indeed, in line with critical feminist qualitative research, I must maintain "continued close attention to representation, voice, and text" (Olesen, 2018, p. 163). Thus, I often checked my interpretations with the parents of focal players and the players themselves for trustworthiness. Specifically, I conducted these member checks in various forms, including texting, emailing, and calling participants in order to verify my understanding of their perspectives. Included in these member checks was my asking the adult participants to read at least one draft of this article before publication, and to share the draft(s) with their children if they wanted to. All participants supported everything we communicated about, including what they read in draft form. I also consulted with a colleague, whose research focuses on gender identity in children, regarding my interpretations and understanding of the data.

\section{Participants' Voices}

I don't like when people call me a boy. It's very annoying and I want it to stop. I feel mad when they say that. I want people to know that girls don't need to look like what stereotypical girls look like in books and movies. And you can't just assume someone's gender just by looking at them. - Alex, age 10

All four focal children were players on a particularly successful and close-knit team, and the young team's athleticism and winning record caught the attention of many within the region.

Each of these players are frequently misgendered, defined as others incorrectly assuming one's gender. Specifically, each of these children are frequently assumed to "be boys." Although the children experience misgendering in almost every aspect of their lives - school, public spaces, bathrooms, and athletics - the focus here is on their experiences related to soccer. Parents of the focal children reported that at each and every game over the span of three years, regardless of geographical location, their children were misgendered. Referees, coaches, team managers, and parents of opposing team members would ask why the all-girls team consisted of four boys. Regardless of the fact that each player was officially registered and rostered as female, adults at each game assumed the players were boys.

This happened so often, in fact, that Bobetta's dad took it upon himself to approach the opposing sideline during warm-ups to 
explain that everyone on the team was indeed a girl, and to answer any questions they might have. Similarly, partway through her first season of coaching the team, and after witnessing the constant misgendering - and worse-occurring at games, Coach Rachel began to approach referees and opposing coaches before games to reassure them that indeed this was an all-girls team.

These proactive measures rarely helped, however. Unfortunately, the discrimination these young athletes faced was not limited to misgendering; instead, in many instances the perpetrators did not believe the children when the explained they were girls. Indeed, the children endured countless instances of what I call gender identity denial. That is, despite one's insistence regarding their gender identity, others tell them they are wrong, thereby denying their stated gender identity. In essence, gender identity denial refuses one the right to claim their own gender identity. In this case, these young athletes often responded to misgendering by stating, "No, I'm a girl," and were then met with disbelief and insistence that they were, in fact, boys. This gender identity denial was enacted directly to the players and their parents and coaches. Data analysis of the players' experiences as soccer players who are frequently misgendered showed that gender identity denial was the most salient theme that ran across all of the data, for all the participants. Subsequently, further analysis showed that this gender identity denial is divided into three related categories: 1) Accusations of Lying and Cheating, 2) Objectification of Young Bodies, and 3) Females as Second-Class Athletes. Because all participants had very strong emotional responses to the instances of accusations of lying and cheating, a discussion of the emotional impact of this specific type of gender identity denial is included as a sub-section of the section titled Accusations of Lying and Cheating.

\section{Accusations of Lying and Cheating}

When the children were 10 and 11 years old their team won a tournament for the first time. After the final whistle blew, the newly minted champions shook their opponents' hands and ran to the referee, excitedly jumping up and down, each team member peppering him with questions: "Where do we get our medals?"; "Is it a medal, or a trophy?"; "Do we get them now, or do we have to wait?"; "Will they take our picture?" The referee replied, "You didn't deserve to win. You don't deserve medals. You had boys on your team, and that's cheating." Recalling that moment, Sam explains,

We hadn't won any tournaments yet. So finally getting a win was like, 'Yes, we did it!' and then all of a sudden, they're like, 'No, you don't deserve that.' And we're like, 'Why?' It's just heartbreaking. It just sucks when that happens. We were all celebrating and then they're like, 'NO. You don't deserve these medals.'

Despite the children, their parents, and their coach explaining that in fact all players were girls, the (female) coach of the team the Eagles beat in that final game immediately filed a formal complaint against the Eagles for cheating. She claimed that the team consisted of boys and that the team lied about the identities of its players. Further, she argued, the team was not eligible to win the tournament and their medals should therefore be taken away. The Eagles' coaching director responded to the complaint, and the complaint was eventually dismissed.

Months later, in the group interview, Sam further reflected on this incident:
Sam [addressing her teammates]: Remember in U10, when we won the tournament and they were like, 'Don't give them their medals,' and our entire team was like, 'Oh my god, you idiots! What are you thinking?' That was good cause like our entire team like stood up to them and were like, 'That's horrible. Everyone was like backing us up and stuff and it was really nice.

Emily: Didn't coach Rachel and the parents make a letter to them? Like telling them how stupid they were?

Sam: Yeah. That made me happy ... and, that trophy was sooooo big! That was a good trophy!

In a separate incident, as the Eagles warmed up during a regional tournament, the opposing team's manager (who is also the mom of player on the opposing team) complained to the coach that there were boys on the Eagles. Not satisfied with the answer, she approached the players, challenging them with, "If you really are girls, then what are your names?" The players stated their names, which did not satisfy her. She asked repeatedly, checking names against the roster in her hand. She then approached parents, demanding to see the short-haired player's passports and birth certificates, at which point many of the players became upset and started to cry. Emily recalls running to her mom on the sideline and crying, "Mom! She thinks we're boys! She won't believe us!"

Parents of the short-haired and long-haired players became aware of what had just happened and intervened to explain that each of the players was rostered correctly and that checking birth certificates had been part of the rostering process. The opposing team's manager continued to demand to see either passports or birth certificates, or both. Alex recalled hearing this manager say, "I just really need to see their birth certificates because I need to see if they were born girls and if they are girls." Alex said she went on to insist, "It's hard to tell if they're girls or boys because they're not fully developed."

In response, a mother of a long-haired player on the Eagles pointed to her daughter as the team resumed warming up, some still in tears, and said to the opposing team manager, "Do you also need to see my daughter's birth certificate? Or is her ponytail good enough for you?" The manager then responded, "No, she's fine. I don't need to see her birth certificate."

Alex's dad, Pierre, part of the coaching staff, recalled this particularly troubling experience:

This woman had quizzed the girls, asking them to state their names, and the girls were upset by this and there were at least a couple of them who were crying. I remember I said to this woman clearly, 'I don't actually have a problem with your uncertainty, although that does insinuate that we were cheating or lying about the kids' identities. The biggest problem I have is that you decided to go up to our girls about this and that's really harmful to them.' I told her, 'If you ever have a question like this, you've got to talk to our coach or the referee or the tournament official. Under no circumstances can you approach the kids directly.' And she just shrugged and said, 'I'm sure they get this all the time. I don't see what the big deal is.'

The Eagles went on to qualify to play in the final game of the regional tournament, and the team manager/parent who accosted the players two days earlier continued to insist that these children, their parents, and coaches were lying. Parents of the four focal players reported that during the final game, she was pointing 
angrily at the four short-haired players, complaining loudly to nearby fans, "it's just not fair-those are boys."

A year later, and again at Regionals, players and parents became aware that an adult watching a game on the adjacent field was complaining loudly about the Eagles having boys on their team. Parents gleaned that this adult was angry because her daughter's team would likely face the Eagles in the course of the tournament, and it was not fair that her daughter's team would have to play against a co-ed team. As the Eagles started their postgame huddle, this parent's complaints got louder. According to Pierre, Alex's dad who was an assistant coach at the time, the players were distracted by her and were not able to focus on what was being discussed in the post-game huddle.

In his role as assistant coach, Pierre approached this parent in the hopes of calming her down and thus allowing the head coach to continue the post-game huddle. Pierre explained that she told him, "But my daughter is going to play your team, and that's not fair," and, "just so you know, everyone over there [at the adjacent field] is talking about this, and they are not happy either." At this point, the head coach, Jack, approached and insisted his team was an all-girls team. At that point, Pierre explained, things escalated:

She got irate and pounded her chest like people do before a fight. She was very close to throwing a punch at Jack. It only ended because her husband came over, told her to stop, put his hands on her shoulders, and led her away from the fields.

Pierre then went on to reflect on that experience, and explained, "I think what makes me most upset when this kind of thing happens is that this is supposed to be a space for the kids, and for play. These adults are taking away from these kids' experiences in sports."

Emotional Impacts. These experiences of discrimination, gender identity denial, and accusations of cheating have lasting effects on the players, coaches, and family members. Coach Rachel recounts a moment in which the effect on her players was crystal clear to her:

There was one moment . . . it crushed me as a coach. After explaining to that coach before the game that they were all girls, I walked back to the team and I remember, Emily was like, 'They think we're boys,' looking down, so sad. And you kind of see this this child who was confident to start with and now all of sudden she kind of just deflated.

Coach Rachel went on to explain the impact on her:

On many levels I get mad, but mostly for the girls, because they are $10,11,12$, and they are struggling with many things in their own world, and to have an adult say those things about them ... someone judging and saying those things can be harmful to them. There is part of this that [is about] the integrity of the girls, the integrity of the parents, the club, myself. Why would we cheat to play soccer? It just doesn't make sense. And there is that piece, too, of like, girls can be good at soccer and they don't have to be boys to be good!

Emily, explaining how she felt when the opposing team's manager "quizzed" her on her name, shared the following:

She just wouldn't stop. It's kind of like unexplainable how upsetting it was. That was really, really bad. It's the worst feeling I've had. [When she came up to us] I was just frozen. I was frozen. Like, 'How? Why? Like why can't you leave us alone?' I started crying. I knew she wasn't going to believe us.
Emily's parents, Grace and Patrick, explained that that incident was formative for Emily, in that she realized that adults can be mean to kids, even when the kids are telling the truth. Part of my conversation with them follows:

Patrick: [Emily] didn't understand why this big person was being mean. It was an adult being mean and she didn't understand. I think that was her first encounter with someone-

Grace: -and then that woman was not believing them. She kept asking their names as if at one point they were going to screw up their names and say something else. . . I think that was the first time that [Emily] told the truth and wasn't believed by an adult.

Alex shared, "I cried a lot, especially when I was littler," and Bobetta explained, "My stomach feels, like, really queasy." When I asked Bobetta's dad, Milo, how this affected him, he discussed feeling intense anger at seeing his daughter being "bullied by adults," as well as some hesitation regarding giving "the pre-game speech" to the opposing fans before games. Milo explained:

Days before our last game, I was thinking, 'I really better give the speech.' It makes my stomach turn and I think maybe I just won't do it, then I think, 'That's chicken. These girls are out there just wanting to have fun. You gotta do it regardless of what the outcome is.' And then there's times that I'm like, 'Somebody, just fire back at me, please. Give me a reason to release some of this pent-up anger I have in this tight little ball of hate right here [gesturing with a clenched hand to his stomach].' . . . But then I think, [the kids] are a hell of a lot braver than me. So, I have nothing to be afraid of to go talk to a bunch of parents and just tell them to chill out and let the kids have fun.

Alex shared what it feels like to be the target of endless incorrect assumptions regarding her gender, including gender identity denial:

Making assumptions, sometimes you can be right, but a lot of times you're wrong. If you assume the wrong gender, for the other person, it hurts them more than it shows on the outside. Like they may just smile and say, 'I'm a girl,' but on the inside they're frowning and doubting themselves because every time someone does that it's like a slap in the face.

I interviewed Emily's older sister Tobin, who has long hair and is also a competitive soccer player. It was clear to me that Tobin wants to protect Emily and that she worries about her. I asked her what it feels like when she witnesses the misgendering and gender identity denial Emily faces:

Tobin: I just get hot and my eyes just get blank. . . . I get a nervous stomach and I just start shaking my leg because I didn't know what they will say.

Julie: What do you want people who think she's a boy to understand?

Tobin: That it's ok for girls to have short hair and play sports and be confident and strong and they need to get over themselves and people can be whatever they want and they just need to understand. The world is changing and stereotypes are changing and it's going to be ok. . . . She's my sister and I feel bad (buries her face in her hands and cries). I just don't 
want her to hurt. That's my sister. I want her to own it and want it and be ok with it.

\section{Objectification of Young Bodies}

Objectification of these children's bodies is omnipresent in each instance of gender identity denial these young athletes face. Specifically, at the regional tournament discussed above at which the opposing team manager demanded passports and birth certificates, Alex was acutely aware that the focus was on her and her teammates' bodies, not just their hair. This came up in an interview when I asked her why she thinks people misgender her, and part of that conversation follows:

Julie: Why do you think people look at you and just assume you're a boy?

Alex: Because of my hair. And, um, the way my body's shaped.

Julie: What do you mean?

Alex: Um, a lot of stereotypical girls are skinny. They barely have, like, any muscle.

Julie: Okay so, you're saying that people misgender you because of your hair and that you're muscular. Any other reasons that you think it happens?

Alex: I guess it's especially hard to know if you're a girl or boy at a young age.

Julie: Why?

Alex: Because your body hasn't fully developed yet (Alex gestures "air quotes" as she says "fully developed"), like that lady said at Regionals (Alex rolls her eyes). You know, you shouldn't need to have someone fully developed to know if they're a boy or a girl. I mean you shouldn't assume in the first place. You shouldn't be that stubborn anyway.

At yet a different tournament, I noticed an animated-and clearly angry - conversation between a man and woman on the sideline as the Eagles played just a few feet away. These adults were pointing toward the Eagles' short-haired players, shaking their heads, and speaking loudly. As they were gesticulating toward the field, Alex's dad, Pierre, was walking toward the bathrooms at the far end of the field, which took him close to this conversation. I could see that the man then leaned in to Pierre and started yelling and pointing angrily toward the players and at Pierre.

Pierre later explained to me that as he was walking to the bathroom, he overheard parts of the conversation. Specifically, he heard phrases such as, "They can't have boys on their team!" and "This is an all-girls tournament!" and "This is cheating-it's not fair!" Pierre explained that he just shook his head as he walked toward the bathroom and thought, "Here we go again," hoping the conversation would be done by the time he returned to the sideline to watch the game. When he walked by them again, however, the conversation had become louder. Some of my interview with Pierre follows:

Pierre: So, as I walked by, I smiled and said, 'They're all girls.' The guy said, 'WHAT?' So I repeated, 'They're all girls.' Then he said, 'There's no way those are girls. You're not going to tell me that THAT'S a girl!' And he was pointing right at
Alex, and maybe at Bobetta, too. I just said, 'Yep, that's my daughter. She's a girl.'

Julie: Did he believe you?

Pierre: No. He just kept saying 'You're wrong. It's not possible.' I said something like, 'Man, listen to yourself. Educate yourself. They are girls, with short hair.'

In addition to adults referring to the young athletes as "that," objectification also came in the form of adults judging the level of attractiveness of these children. As I watched an Eagles game next to Alex's 14-year-old brother, an adult fan of the opposing team seated in front of us remarked, "How can this team have boys on it? That's not fair." In response, a teenager seated with this adult said, "This team is all girls-that's actually a girl," indicating Alex as she dribbled through two players and accelerated up the sideline. The adult then scoffed, with her eyes on Alex, "Well, that's just not attractive." I watched as Alex's brother immediately walked to the other end of the sideline, his head down, and remained there for the rest of the game. I later asked him what he thought about the comment, and he said, "It was just so mean. And so dumb. How can someone say something like that?"

\section{Females as Second-Class Athletes}

As the Eagles and their opponents warmed up for a game, the parents of the opposing team were particularly vocal (and angry) about their conviction that the Eagles had "boys on their team." Earlier in the season while playing this team, accusations of cheating were leveled at the Eagles. Bobetta's dad's efforts to allay concerns were met with anger, disbelief, and accusations of cheating, even before the game started. Coach Rachel approached the opposing coach during warmups, also hoping to allay any concerns. Rachel explains:

I went up to him and was like, 'Hey, I know we had this issue last fall, but I want to remind you that we are an all-girls team.' And he kind of went into this whole thing of, 'I don't really believe you, they could be boys they could be girls, it's not fair to my team. You know, if a boy entered a female race, the boy would win no matter what because the boy is a better athlete.' And he referenced the Olympics, like if a man entered a women's Olympics [event] that's considered cheating. And I go, 'They are all girls though,' and he goes, 'You are telling me that but I don't really believe you.'

And I was like, 'They are all girls.' And the girls were just warming up while this whole exchange was going on. I went to get the roster, because the roster has the "F" $\mathrm{s}$ " [for female] and I explained to him, 'This is from [the league], it means that you are verified with a birth certificate and a picture of the player, so the fact that this has " $F$ " means that that's what was on the birth certificate. He was like, 'I don't believe you.' At that point, I knew if I didn't walk I away I would probably end up doing something that I would regret.

Bobetta's mom, Nicole, had also approached this coach before the game. The coach, still denying that the athletes were girls, said, "But they are too good to be girls. They move like boys." Nicole recalled the conversation, telling me, "it is seared into my brain." Nicole went on to recall the rest of the conversation, saying, "Then I said, 'so because they move athletically they must be boys?' He kinda shrugged and nodded and looked at me as if to say, 'Yes, exactly.", 
In addition to subscribing to-and perpetuating-stereotypical ideas about how females "should" look and "should" move, adults who came into contact with this team also fell victim to the notion that girls are inherently weaker, more passive, and less aggressive than boys. Alex's mom, Miranda, recalled a separate instance in which she approached an angry dad of an opposing player. During the game, she explained, he was talking loudly to parents near him, complaining about the "boys on the team." Miranda said,

He was swearing a lot, almost yelling. I'm sure the kids on the field could hear him. So I just decided, 'I'm gonna walk up to him and explain. I have to say something, I can't let this go.' So I said, 'Excuse me, I heard you complaining. There are no boys on this team, and they have been through a lot with people saying they are boys. They were born girls, they identify as girls.' Then he got in my face and said, 'Yeah. Whatever! I don't want your boys to hurt our girls! Someone is gonna get hurt! I just want to protect our girls.' And the crazy thing is, the other team was fouling all over the place and playing out of control. Our team wasn't even fouling.

When I asked the players during the group interview if they thought people would accuse their team of cheating if their team wasn't exceptionally good, their awareness of the notion of females being considered to be second-class athletes was clear. Part of our conversation follows:

Julie: So, do you think people would accuse the team of cheating if your team wasn't that good?

\section{All at once: NO!}

Bobetta: Because they automatically assume that boys are, like, really good. So when they think we're boys I feel not more mad at them cause they called me a boy, but [mad at them because] if we wouldn't have won, then they wouldn't have said anything.

Sam: And also, I think it's annoying that they have to come up with some way to be, like, 'They shouldn't have won-[all talking at once, unintelligible]

Sam: Yeah, like if we all had long hair they would come up with a different reason why we shouldn't have won or some crap like that.

Julie: So, if you all had long hair-

Alex: I think they would've just said, 'Good game, your girls are really good.'

Julie: So, it sounds like all four of you think that if your team wasn't that good, and other teams were beating you more than you were winning, it wouldn't be a big deal?

Bobetta: Yeah. They'd be like, 'Eh, we won, we don't care' [shrugs].

Julie: Do you think they would still think you are boys?

Emily: They would probably still think that [we were boys] but they wouldn't voice it-

Sam: They would be like, 'Yay! We beat boys!' or some crazy thing like that.
Bobetta: Yup.

All at once: [signs of agreement, including laughing, rolling eyes, nodding]

\section{Conclusions and Implications}

... the female athlete — and her body_-has become contested ideological terrain. - Messner, 2007, p. 32

We have seen that the young athletes discussed here have endured countless instances of misgendering, many instances of gender-identity denial, and even accusations of cheating. We have also seen that their young bodies were judged, objectified, and policed, and were indeed turned into "contested ideological terrain." We have seen adults perpetuate oppressive notions about female athletes, even as they ostensibly support their own female teams and family members, and we have seen adults directly challenge children about their right to claim their own identities. For Alex, Bobetta, Emily, and Sam, sport was not always a welcoming and safe space. Sport, which ostensibly welcomes and values strong, athletic, "tomboy-like" girls, seems to have its limits with regard to how far it is willing to go in its acceptance. Adults responsible for supporting, organizing, and regulating youth female sport seem to have internalized the omnipresent damaging messages about girls and female athletes, and appear to maintain specific and fixed notions of what it means to "do" femininity in an acceptable manner. These players were subject to "'othering' discourses of ... gendered bodies" by stepping outside the "norm" (Hill, 2015, p. 680). It is clear that even within competitive youth sports, normative notions of gender expression can be privileged, and those outside this norm are punished.

It seems that many of the adults charged with being role models and shepherding these children through their development as athletes decided these nonconforming players were too powerful, too good, too strong, and had stepped outside acceptable parameters of being female. These adults seem to have subscribed to the "fair play" discourse of sport (Pieper, 2016) and the flawed belief sport is inherently a level playing field (Cooky \& Dworkin, 2013). In addition, we saw evidence of "fears of powerful, nonfeminine athletes" (Pieper, 2016, p. 8) on the part of these adults, and, just as has happened throughout history, they stepped in to stop these athletes who were, simply put, too powerful. These adults exerted power over (read: oppressed) these children and their advocates in multiple ways. They enacted in gender policing (Krane, 2019), sex control (Bavington, 2019), and gender identity denial (which included accusations of cheating, attempts to ban them from tournaments, stripping medals and trophies, and demanding government-issued documentation to prove their identities). When the children and their adult advocates pushed back, the perpetrators denied once again.

Importantly, the perpetrators here were not only men: This exceptionally strong girls' team with four short-haired, skilled players, drew the ire of many referees and opposing coaches, managers, and parents_-including mothers, female referees, and female coaches. It is hard to imagine that the gender identity denial and angry accusations of cheating would have occurred if the team were not as talented, strong, or successful. Although there is no definitive way to know, it is doubtful the players' identities would be challenged if the Eagles were an average team or had a losing record. Just as "only stronger than average women aggrieved the IOC's sensibilities" throughout history (Pieper, 2016, p. 8), we are 
left to wonder if only better than average female gender nonconforming youth soccer players aggrieve adults' sensibilities as well.

When I asked Coach Elliott, part of the Eagles' coaching staff, what she would like to say, if given the chance, to the adults who perpetrated these harmful accusations and gender identity denial, she said, through tears:

Part of me wants to yell at them and tell them to leave [the kids] alone, and part of me wants to ask them, 'How can you say that? What are you so afraid of? What is going on for you? What happened to you that you have to do this to a 10 -yearold kid?'

It is likely that the confluence of centuries-long gender stereotyping and discrimination, including gender policing in sport and the problematic media coverage discussed above, have created fertile ground for the adult behavior examined here. As discussed above, sexism writ large and with specific regard to sport is omnipresent, including within popular culture. All of us, to varying degrees, are susceptible to the sexist messages that surround us daily as well as the sexism inherent in many institutions, including sport; and the adult perpetrators in this article are no exception. An important future area of study is the examination of the perspectives of the adult perpetrators of the kinds of discrimination discussed here. Ostensibly, they simply want the game to be "fair" and they want to "protect" their female players from stronger "boys." Repeated attempts by Eagles' parents and coaches to help these adults understand and thus accept the athletes' identities did not improve the behavior or increase understanding. These adults were steadfast in their conviction that they were "right" in their protests and accusations of cheating, and that their team was being "wronged" and lied to. This behavior, however, has potentially farreaching impacts. Pieper's (2016) words about the origins and impacts of the IOC "sex testing" polices are pertinent here. Pieper writes, "The belief that any man could don a wig or a skirt and defeat all women in athletic competition both promoted sport as a male domain and diminished women's skills and talents" (p. 8).

It's also possible, in addition to the contributing factors discussed above, that the marked increase in visibility of transgender identities within the last five years has, in a sense, created a "backlash" for the young participants. We have seen the transgender community publicly fight for social justice; we have seen prominent articles featuring transgender children and adults in popular magazines, television shows, and movies; we have witnessed the public transition of celebrities; and the success and popularity of children's books featuring transgender characters which convey the importance of acceptance and equity for all identities. We have also seen controversy regarding federal policies on gendered bathrooms in relation to transgender rights as well as controversy related to the rules of participation for transgender (and suspected transgender) athletes in the Olympics.

Thus, it is possible that this increased visibility-and controversy - may have contributed to some of the adults' perceptions of these children. It is possible that 10 years ago, before transgender identities were as visible as they are now, some of these adults may have more readily accepted that these children were athletic females with short hair. Period. It is possible that for the first time in their lives, these adults were forced to consider the complexities of gender identity as well as the various ways of being female. And, because these adults viewed these players as too good and too powerful to "really" be girls, it is possible that they made a rash assumption that these children's sex assigned at birth must be male and they were transitioning to female.
Significantly, the harmful assumptions, frequent gender identity denial, and accusations of cheating not only harm the targets of this discrimination, but also give powerful and damaging messages to all. For example, the opposing female athletes are learning that when they lose to the Eagles, it is not because the Eagles' players are strong, talented, and hardworking; rather, it is because girls simply cannot be that good-only boys can. Put simply, they are learning that they themselves, and all other females, are perceived as inferior to males. The siblings, other children, and even adults on the sidelines are learning the same thing. In addition, they are learning that gender (and sex) is a binary concept. Further, they are learning that girls "should" look and move only in certain "acceptable" ways: girls should appear stereotypically feminine (which includes long hair) and should not move too athletically or aggressively. If these expectations are not met, they are learning, then problems occur.

With a staggering $49 \%$ of females dropping out of sport before they reach puberty (UN Women Statistics, as reported in Perasso, 2017), sporting organizations should be doing everything possible to retain female - and all gender-athletes. Part of the efforts to retain athletes must include promoting the well-being of youth through sport—not threatening it. As we have seen, the well-being of the participants in this study stands to be threatened through the discrimination and identity threat (Steele, 2010) they experience.

This study has a number of implications for institutions of higher education and practitioners alike, and each is aimed at interrupting these power dynamics and moving toward social justice for all young athletes whose gender presentation doesn't always match expectations. First, it is crucial that scholars and those involved in educating future sport managers, coaches, and academics possess the deeper, more nuanced, and more accurate understanding of sex and of gender that this study calls for. It is also the responsibility of those within higher education who prepare future leaders in sport to explicitly address issues related to gender identity and discrimination with their students.

Additionally, coaches, referees, and sport administrators must also work to gain a deeper understanding of gender identity and expect the same from their peers and staff members. A necessary part of this greater understanding is having the language with which to talk about the gender-based discrimination examined here. As I have argued elsewhere, the language we use matters (Minikel-Lacocque, 2013) and is part of working toward social change. Thus, practitioners must become fluent in their understanding of and use of the terms misgendering and gender identity denial in their work with children. Further, it is imperative that these practitioners believe children about their identities and instruct team parents and other fans to do the same. It is the duty of club managers and coaching directors to create a culture of acceptance and advocacy for children. In tandem with this understanding must be the incorporation of what Travers (2014) calls "egalitarian values" for all those involved in sport-players, coaches, referees, fans, and administrators. My hope is that learning from youth and their supporters about their experiences with gender identity discrimination will move the needle toward those "egalitarian values." These deeper understandings would pave the way for structural change, and a logical place to start that change is Travers's (2014) recommendation that within the sex-segregated team structure, youth be allowed to join/tryout for either team with no questions asked.

Given that youth sports are still dominated by segregation along the sex binary, practitioners must understand the league rostering rules as well as their sport's policy on discrimination. 
Although the notion of a coach finding a group of boys who agree to lie about their identities and masquerade as girls in order to win games, and that all the parents and coaches are colluding with the lie, is preposterous and illogical, we have seen that emotions (including fear) can take precedence over logic. Thus, rostering rules must be clear and transparent to all. If gender is listed on the team roster, there is no cause for further discussion or questioning of the gender of the players. And, all employees of a sport club should be aware of and follow their sport's policy on discrimination and on inclusion. For example, U.S. Soccer Federation's policy on inclusion states that its organization is open to all, without discrimination of any kind, including that based on gender identity or gender expression. Further, it states that with regard to team membership on all gender-based amateur teams, "a player may register with the gender team with which the player identifies" (U.S. Soccer Federation Policy Manual, 2019-2020, p. 53).

If the above recommendations are followed, there should be no more voicing of suspicions or accusations of cheating related to gender in youth sport. And, if the above recommendations are followed, the bodies of female, "gender identity complex" (Miller, 2019), and gender nonconforming athletes would cease to be "contested ideological terrain" (Messner, 2007, p. 32). If there remain any concerns regarding players' identities, however, it is the responsibility of coaches and other adults to direct those concerns to coaches and referees-never to the children themselves. Indeed, it is the responsibility of coaching directors to educate their coaches, players, and club parents about gender, gender stereotypes, and gender identity denial. Referee associations must do the same. This education - and thereby advocacy-is necessary if we are to attract, retain, and support youth from all backgrounds and identities in sport. If adults can create a more "supportive environment" for those who are often "othered" in youth sports, it is more likely athletes like the children in this study could help "shift gendered norms" and "expand available and acceptable" ways of defining and expressing gender (Hill, 2015, p. 680). Specifically, this education and advocacy are necessary if we are to reject long-held gender stereotypes, abolish the all too common discrimination discussed above, and, in the words of Eagles coach Elliott, make it possible for all youth to "just be who they are and be comfortable in their own skin," regardless of the length of their hair and the way they move on the field.

\section{Note}

1. Please see Dworkin, Swarr, and Cooky (2013) for an analysis of the Caster Semenya case.

\section{References}

Anderson, E. (2002). Openly gay athletes: Contesting hegemonic masculinity in a homophobic environment. Gender \& Society, 16(6), 860-877. https://www.jstor.org/stable/3081938. doi:10.1177/ 089124302237892

Bavington, L.D. (2019). Sex control in women's sport: A history of the present regulations on hyperandrogenism in female athletes. In V. Krane (Ed.), Sex, gender, and sexuality in sport: Queer inquiries (pp. 181-201). New York, NY: Routledge.

Charmaz, K., Thornberg, R., \& Keane, E. (2018). Evolving grounded theory and social justice inquiry. In N.K. Denzin \& Y.S. Lincoln (Eds.), Handbook of qualitative research (pp. 411-443). Thousand Oaks, CA: Sage.
Cooky, C., \& Dworkin, S.L. (2013). Policing the boundaries of sex: A critical examination of gender verification at the Caster Semenya controversy. Journal of Sex Research, 50(2), 103-111. PubMed ID: 23320629 doi:10.1080/00224499.2012.725488

Cooky, C., Messner, M.A., \& Musto, M. (2015). It's dude time! A quarter century of excluding women's sports in televised news and highlight shows. Communication \& Sport, 3(3), 261-287. doi:10.1177/ 2167479515588761

Dworkin, S.L., Swarr, A.L., \& Cooky, C. (2013). (In)justice in sport: The treatment of South African star Caster Semenya. Feminist Studies, 39(1), 40-69. Retrieved from https://www.jstor.org/stable/23719289

Fontana, A., \& Frey, J. (1998). Interviewing: The art of science. In N.K. Denzin \& Y.S. Lincoln (Eds.), Collecting and interpreting qualitative materials (pp. 47-78). Thousand Oaks, CA: Sage.

Glense, C., \& Peshkin, A. (1992). Becoming qualitative researchers: An introduction. White Plains, NY: Longman.

Gubrium, J.F., Holstein, J., Marvasti, A.B., \& McKinney, K.D. (2012). Introduction: The complexity of the craft. In J.F. Gubrium, J. Holstein, A.B. Marvasti, \& K.D. McKinney (Eds.), The SAGE handbook of interview research: the complexity of the craft (2nd ed.; pp. 1-5). Thousand Oaks, CA: Sage.

Hill, J. (2015). Girls' active identities: Navigating othering discourses of femininity, bodies, and physical education. Gender and Education, 27(6), 666-684. doi:10.1080/09540253.2015.1078875

Human Rights Campaign. (2018). Gender-expansive youth report. Retrieved from https://assets2.hrc.org/files/assets/resources/GEreport1.pdf?_ga= 2.42220647.31491002.1575747043-187083116.1575747043

Johnson, J.M., \& Rowlands, T. (2012). The interpersonal dynamics of indepth interviewing. In J.F. Gubrium, J. Holstein, A.B. Marvasti, \& K.D. McKinney (Eds.), The SAGE handbook of interview research: the complexity of the craft (2nd ed.; pp. 99-113). Thousand Oaks, CA: Sage.

Kane, M.J. (1995). Resistance/transformation of the oppositional binary: Exposing sport as a continuum. Journal of Sport and Social Issues, 19(2), 191-218. doi:10.1177/019372395019002006

Krane, V. (2019). Glossary. In V. Krane (Ed.), Sex, gender, and sexuality in sport: Queer inquiries (pp. 238-249). New York, NY: Routledge.

MacKinnon, C. (1983). Feminism, marxism, method and the state: toward feminist jurisprudence. Signs, 7, 515-544. Retrieved from https:// www.jstor.org/stable/3173853

Mele, C. (2017, June 6). 'They thought I was a boy: Short-haired girl barred from soccer tournament. The New York Times. Retrieved from https://www.nytimes.com/2017/06/06/sports/girl-soccer-player.html

Messner, M.A. (2007). Out of play: Critical essays on gender and sport. Albany, NY: State University of New York Press.

Miller, S.J. (2019). About gender identity justice in schools and communities. New York, NY: Teachers College Press.

Minikel-Lacocque, J. (2013). Racism, college, and the power of words: Racial microaggressions reconsidered. American Educational Research Journal, 50(3), 432-465. Retrieved from http://aer.sagepub.com/ content/50/3/432. doi:10.3102/0002831212468048

Minikel-Lacocque, J. (2019). The affect-responsive interview \& reexamining in-depth interviewing: What we can learn from therapy research. Qualitative Inquiry, 25(10), 1038-1046. doi:10.1177/ 1077800418792941

Oleson, V. (2011). Not without a shout: Acts of activism...p politics of possibility. Cultural Studies-Critical Methodologies, 11, 403-405. PubMed ID: 32294208 doi:10.1177/1532708611414673

Oleson, V. (2018). Feminist qualitative research in the millennium's first decade: Developments, challenges, prospects. In N.K. Denzin \& Y.S. Lincoln (Eds.), Handbook of qualitative research (pp. 151-194). Thousand Oaks, CA: Sage. 
Perasso, V. (2017, October 23). 100 women: Is the gender pay gap in sports really closing? The BBC World News. Retrieved from https://www. bbc.com/news/world-41685042

Pieper, L.P. (2016). Sex testing: Gender policing in women's sports. Urbana, IL: The University of Illinois Press.

Roulston, K. (2010). Reflective interviewing: A guide to theory and practice. Thousand Oaks, CA: Sage.

Roulston, K. (2012). The Pedagogy of Interviewing. In J.F. Gubrium, J. Holstein, A.B. Marvasti, \& K.D. McKinney (Eds.), The SAGE handbook of interview research: the complexity of the craft (2nd ed.). Thousand Oaks, CA: Sage.

Schwandt, T.A. (2001). Qualitative Inquiry: A dictionary of terms (2nd ed.). Thousand Oaks, CA: Sage.

Seidman, S. (1997). Difference troubles: Queering social theory and sexual politics. Cambridge: Cambridge University Press.

Smith, L.T. (2005). On tricky ground: Researching the native in the age of uncertainty. In N.K. Denzin \& Y.S. Lincoln (Eds.), Handbook of qualitative research (pp. 85-107). Thousand Oaks, CA: Sage.

Stake, R.E. (2005). Qualitative case studies. In N.K. Denzin \& Y.S. Lincoln (Eds.), Handbook of qualitative research (pp. 443-466). Thousand Oaks, CA: Sage.

Steele, C. (2010). Whistling vivaldi: How stereotypes affect us and what we can do. New York, NY: W.W. Norton.
Travers, A. (2006). Queering sport: Lesbian softball leagues and the transgender challenge. International Review for the Sociology of Sport, 41(3-4), 431-446. doi:10.1177/1012690207078070

Travers, A. (2008). The sport nexus and gender injustice. Studies in Social Justice, 2(1), 79-101. doi:10.26522/ssj.v2i1.969

Travers, A. (2014). Transformative gender justice as a framework for normalizing gender variance among children and youth. In E.J. Meyer $\&$ A. Pullen Sansfacon (Eds.), Supporting transgender and gender creative youth (pp. 54-68). New York, NY: Peter Lang.

Travers, A. (2019). Transgender kids and sport participation. In V. Krane (Ed.), Sex, gender, and sexuality in sport: Queer inquiries (pp. 163177). New York, NY: Routledge.

U.S. Soccer Federation Policy Manual. (2019-2020). Retrieved from https://www.ussoccer.com/governance/bylaws

Waldron, J. (2019). Four perspectives for understanding LGBTIQ people in sport. In V. Krane (Ed.), Sex, gender, and sexuality in sport: Queer inquiries (pp. 15-32). New York, NY: Routledge.

Weber, J., \& Barker-Ruchti, N. (2012). Bending, flirting, floating, flying: A critical analysis of female figures in 1970s gymnastics photographs. Sociology of Sport Journal, 29, 22-41. doi:10.1123/ ssj.29.1.22 